\title{
The Impact of Iron and Folate Adherence on the Prevalence of Anaemia in Pregnant Nigerian Women
}

\author{
Akinola Oyekemi Ifeoluwapo ${ }^{1, *}$, Uwaibi Noel $^{2}$, Nwagu Marcellinus Uchechukwu ${ }^{1}$, Ohenhen Victor ${ }^{3}$, \\ Egbo Ojevwe Harrison ${ }^{4}$, Erhabor Osarenokemen Julie ${ }^{5}$, Omozuwa Eghosasere Sunday ${ }^{6}$, \\ Omokhua Gabriella ${ }^{7}$, Adeyemi Oluwafemi ${ }^{1}$ \\ ${ }^{1}$ Department of Haematology and Blood Transfusion, Edo University, Iyamho, Nigeria \\ ${ }^{2}$ Department of Community Medicine, Edo University, Iyamho, Nigeria \\ ${ }^{3}$ Department of Obstetrics and Gynaecology, Central Hospital, Benin City, Nigeria \\ ${ }^{4}$ Department of Anatomical and Histopathology, Edo University, Iyamho, Nigeria \\ ${ }^{5}$ Department of Obstetrics and Gynaecology, Stella Obasanjo Women and Children Hospital, Benin City, Nigeria \\ ${ }^{6}$ Department of Obstetrics and Gynaecology, Edo University, Iyamho, Nigeria \\ ${ }^{7}$ Department of Medical Microbiology, Edo University, Iyamho, Nigeria
}

Email address:

oyekemi.akinola@yahoo.com (A. O. Ifeoluwapo)

${ }^{*}$ Corresponding author

To cite this article:

Akinola Oyekemi Ifeoluwapo, Uwaibi Noel, Nwagu Marcellinus Uchechukwu, Ohenhen Victor, Egbo Ojevwe Harrison, Erhabor Osarenokemen Julie, Omozuwa Eghosasere Sunday, Omokhua Gabriella, Adeyemi Oluwafemi. The Impact of Iron and Folate Adherence on the Prevalence of Anaemia in Pregnant Nigerian Women. Journal of Gynecology and Obstetrics. Vol. 8, No. 6, 2020, pp. 179-185. doi: $10.11648 /$ j.jgo.20200806.15

Received: October 27,2020; Accepted: November 5, 2020; Published: November 11, 2020

\begin{abstract}
Introduction: The impact of adherence to taking prescribed medications for chronic illnesses has been widely studied with a view to understanding its role on disease burden. This has been extrapolated to the physiologic pregnancy state, where women are expected to take haematinics due to their susceptibility to anaemia. The prevalence of anaemia in pregnancy is reportedly high with more burden on developing countries. This has led to the recommendation of iron and folate supplements for women during pregnancy. Methods: We set out to determine the level of adherence (and deterrents) to taking iron and folate supplements as well as the prevalence of anaemia in pregnant women (18-45 years old) attending antenatal care at the Stella Obasanjo Women and Children Hospital (SOWCH) and the Central Hospital in Benin City, Nigeria between JulyDecember, 2019. An association between occurrence of anaemia and adherence level was also assessed. Results: 400 pregnant women participated in this study. The mean age $( \pm$ SD) of the study population was $30 \pm 4$ years, mean gestational age $( \pm$ SD) was $31 \pm 5$ weeks. Majority of the women $(82.0 \%)$ were in their third trimester, $17.5 \%$ and $0.5 \%$ in second and first trimesters respectively. Total adherence scores obtained ranged from $0-8$, with $63.5 \%$ being non-adherent to taking their iron and folate supplements. Factors that influenced adherence positively were higher income $(\mathrm{p}=0.00)$ and being employed ( $\mathrm{p}=0.01)$. Top three identified reason for non-adherence were forgetfulness to take prescribed supplement $(62.5 \%)$, feeling too bored to take supplements daily (44.3\%) and unavailability of supplements $(38.0 \%)$. The mean $\mathrm{Hb}( \pm \mathrm{SD})$ was $10.9 \pm 1.1 \mathrm{~g} / \mathrm{dl}$. The prevalence of anaemia in pregnancy was $46.8 \%$, with mild (43.8\%) and moderate (3.3\%) forms only. Of the non-adherent group, $69.7 \%$ were anaemic versus $30.3 \%$ of the adherent group. There was an association between the occurence of anaemia and nonadherence to taking supplements $(\mathrm{p}=0.01)$. Conclusion: There is a high level of non-adherence to taking iron and folate, prevalence of anaemia, and an association between them. Benefits of adherence to these supplements should be reinforced to women of child bearing age.
\end{abstract}

Keywords: Adherence, Anaemia, Pregnancy, Iron, Folate, Impact 


\section{Introduction}

Adherence can be defined as "the extent to which a person's behaviour - taking medication, following a diet, executing lifestyle changes - follows medical advice."[1] The impact of adherence to taking prescribed medications for chronic illnesses has been widely studied with a view to understanding its role on disease burden. [2] This has been extrapolated to the physiologic pregnancy state, where women are expected to take haematinics due to their susceptibility to anaemia. [3] Anaemia, which is a reduction in oxygen-carrying capacity due to reduced haemoglobin concentration, is defined by the World Health Organization (WHO) as haemoglobin concentration $(\mathrm{Hb})<11 \mathrm{~g} / \mathrm{dl}$ in pregnancy. [4] This applies to the first and third trimester, while $\mathrm{Hb}<10.5 \mathrm{~g} / \mathrm{dl}$ is considered anaemia in the second trimester. The WHO further divides anaemia according to severity, into mild $(9.0-10.9 \mathrm{~g} / \mathrm{dl})$, moderate $(7-8.9 \mathrm{~g} / \mathrm{dl})$, severe $(4-6.9 \mathrm{~g} / \mathrm{dl})$ and very severe anaemia $(<4 \mathrm{~g} / \mathrm{dl})$. [4] The prevalence of anaemia in pregnancy is reportedly high with more burden on developing countries. [4] Consequences of anaemia include increased maternal morbidity and mortality, impaired lactation, prematurity, low birth weight or intrauterine foetal death at the extreme. [5] Multifactorial causes are implicated in the aetiology of anaemia in pregnant women, foremost being iron deficiency. This has led to the recommendation of iron and folate supplements for women during pregnancy. [6] In a study in Ethiopia, pregnant women who failed to adhere to taking their supplements had anaemia more than those who did. [7] Reasons identified for poor adherence include low educational status, forgetfulness, fear of side effects and pill burden amongst others. [8,9] We set out to determine the level of adherence (and deterrents) to taking iron and folate supplements as well as the prevalence of anaemia in pregnant women attending antenatal care in Benin City, Nigeria. An association between occurrence of anaemia and adherence level was also assessed.

\section{Materials and Methods}

This study was a cross-section observational study that involved consenting pregnant women (18-45 years old) attending antenatal clinic at the Stella Obasanjo Women and Children Hospital (SOWCH) and the Central Hospital, located in Benin-City, Nigeria. Ethical clearance was granted by the Edo State Hospital Management Board, with reference number, $\mathrm{CH} / \mathrm{A} 40 / 56$. Those who had chronic co-morbidities or conditions predisposing to anaemia, such as haemolytic anaemias, or were actively bleeding or recently transfused with blood ( $<3$ months) were excluded from the study. Using a systematic random sampling technique, participants were recruited for the study (based on the calculated sample size using the formula: $\left.n=Z^{2} P(1-P) / d^{2}\right)$ within a period of 6 months (July-December, 2019). Each participant was administered a questionnaire which addressed demographic parameters and relevant obstetric history to the study, as well as an adherence scale. The eight-item Morisky Medication
Adherence Scale (MMAS-8), a self-report tool, was adopted in this study due to its wide acceptability and usefulness. [10] The questions were scored as follows: Questions $1-7, \mathrm{No}=1$ and $\mathrm{Yes}=0$ while question $8, \mathrm{Never} / \mathrm{rarely}=1$ and all other options $=0$. The scores were added together and minimum and maximum scores of 0 and 8 were obtained. The participants were grouped either non-adherent (0-5) or adherent (6-8).

About $5 \mathrm{mls}$ of venous blood was then drawn aseptically into EDTA anticoagulated bottle to determine $\mathrm{Hb}$ concentration, analysed within 4hours of collection using the Sysmex KX-219 (2006) haemato-analyser.

Anaemia and its severity was determined using WHO criteria; first trimester: $<11.0 \mathrm{~g} / \mathrm{dL}$; second trimester: $<10.5$ $\mathrm{g} / \mathrm{dL}$; and third trimester: $<11.0 \mathrm{~g} / \mathrm{dL}$; mild $(9.0-10.9 \mathrm{~g} / \mathrm{dl})$, moderate $(7-8.9 \mathrm{~g} / \mathrm{dl})$, severe $(4-6.9 \mathrm{~g} / \mathrm{dl})$ and very severe anaemia $(<4 \mathrm{~g} / \mathrm{dl})$ respectively. [4]

Data obtained was analysed using SPSS version 26.0 statistical package. Mean and standard deviation (SD) were used to describe continuous variables and proportions for categorical data. Chi-square analysis was used for group comparisons to determine the significance of observed differences or association where applicable. Level of significance (p) was set at $\leq 0.05$.

\section{Results}

A total of 400 pregnant women participated in this study. Table 1 shows their socio-demographic details.

The mean age $( \pm \mathrm{SD})$ of the study population was $30 \pm 4$ years, $386(96.5 \%)$ women carried singleton fetus, 11 (2.8\%) were with twin gestation while others did not know. Mean gestational age was $31 \pm 5$ weeks. Majority of the women (328; $82.0 \%)$ were in their third trimester, $70(17.5 \%)$ and $2(0.5 \%)$ in second and first trimesters, respectively.

Total adherence scores obtained ranged from 0-8, with 254 $(63.5 \%)$ being non-adherent to taking their supplements and 146 (36.5\%) adherent ones. There was no significant difference in adherence between young women and those with advanced maternal age $(\mathrm{p}=0.29)$ as shown in Table 2 . Pregnant women who were gainfully employed (43.4\%; $108 / 249$ ) were more adherent to taking iron and folate compared to those unemployed $(25.2 \%$; 38/151), a statistically significant finding $(\mathrm{p}=0.00)$. Those who earned above the Nigerian minimum wage were also more adherent $(43.3 \% ; 78 / 180)$ to using these supplements than those who earned less $(30.9 \% ; 68 / 220) ;(p=0.01)$. [11] Educational status of the studied women as well as their husband's occupation (where applicable) did not affect level of adherence $(p>0.05)$. Table 3 reflects the reason for nonadherence. From the scale, the main identified reason for non-adherence was forgetfulness to take prescribed supplement $(62.5 \% ; 250 / 400)$. Other highly proffered reasons were feeling too bored to take supplements daily $(44.3 \%$; $109 / 400)$, unavailability of supplements $(38.0 \% ; 152 / 400)$ and not knowing the importance of taking these supplements $(27.3 \% ; 109 / 400)$.

The mean $\mathrm{Hb}( \pm \mathrm{SD})$ was $10.9 \pm 1.1 \mathrm{~g} / \mathrm{dl}$. The prevalence of 
anaemia in pregnancy was $46.8 \%$ with 188 women falling short of the WHO standard. In terms of severity, only mild $(175 ; 43.8 \%)$ and moderate $(13 ; 3.3 \%)$ forms were found among the participants. The distribution of anaemia by trimesters showed that all women in first trimester $(100 \%$; $2 / 2$ ) were anaemic, $35.7 \%(25 / 70)$ in second trimester were anaemic and $49.1 \%(161 / 328)$ in third trimester were anaemic (Table 4). According to the type of gestation, $45.9 \%$
(177/386) with single gestation were anaemic while $81.8 \%$ $(9 / 11)$ with twin gestation were anaemic. Most of the anaemic women $(86 \% ; 157 / 187)$ were $<35$ years old. Of the non-adherent group, $69.7 \%(131 / 254)$ were anaemic while $30.3 \%(57 / 146)$ of the adherent group were anaemic. The 2 by 2 chi-square test showed a significance between the occurence of anaemia and level of adherence to taking supplements $(\mathrm{p}=0.01)$.

Table 1. Socio-demographic and haematologic characteristics of the study population.

\begin{tabular}{|c|c|c|}
\hline Variable & Frequency $(n=400)$ & Percent (\%) \\
\hline \multicolumn{3}{|l|}{ Age } \\
\hline$<35$ years & 332 & 83.0 \\
\hline$\geq 35$ years & 68 & 17.0 \\
\hline \multicolumn{3}{|l|}{ Educational status } \\
\hline No formal education & 4 & 1.0 \\
\hline Primary & 31 & 7.8 \\
\hline Secondary & 238 & 59.5 \\
\hline Tertiary & 127 & 31.8 \\
\hline Unemployed & 151 & 37.8 \\
\hline Employed & 249 & 62.3 \\
\hline \multicolumn{3}{|l|}{ Income } \\
\hline$<\# 18,000$ & 220 & 55.0 \\
\hline$\geq \$ 18,000$ & 180 & 45.0 \\
\hline \multicolumn{3}{|l|}{ Marital status } \\
\hline Single & 17 & 4.3 \\
\hline Married & 383 & 95.8 \\
\hline Unemployed & 2 & 0.6 \\
\hline Student & 4 & 1.0 \\
\hline Civil servant/ Professional & 61 & 15.9 \\
\hline Unskilled worker & 298 & 77.8 \\
\hline Others & 18 & 4.7 \\
\hline \multicolumn{3}{|l|}{ Type of gestation } \\
\hline Singleton & 386 & 96.5 \\
\hline Multiple & 11 & 2.8 \\
\hline Don't know & 3 & 0.8 \\
\hline \multicolumn{3}{|l|}{ Gestational age } \\
\hline First trimester & 2 & 0.5 \\
\hline Second trimester & 70 & 17.5 \\
\hline Third trimester & 328 & 82.0 \\
\hline Mean $( \pm \mathrm{SD})$ age (years) & $30 \pm 4$ & \\
\hline Mean $( \pm \mathrm{SD}) \mathrm{Hb}(\mathrm{g} / \mathrm{dl})$ & $10.9 \pm 1.1$ & \\
\hline \multicolumn{3}{|l|}{ Adherence group } \\
\hline Non-adherent $(0-5)$ & 254 & 63.5 \\
\hline Anaemic & 187 & 46.8 \\
\hline Non-anaemic & 213 & 53.2 \\
\hline \multicolumn{3}{|l|}{ Distribution of anaemia } \\
\hline Mild & 174 & 43.5 \\
\hline Moderate & 13 & 3.3 \\
\hline Severe & 0 & 0.0 \\
\hline
\end{tabular}

$*_{n}=383$.

Table 2. Association between some socio-demographic parameters and level of adherence among participants.

\begin{tabular}{|c|c|c|c|c|}
\hline Variable & Non-adherent (score 0-5) n (\%) & Adherent (score 6-8) n (\%) & $\mathbf{X}^{2}$ & Pvalue \\
\hline \multicolumn{5}{|c|}{ ( } \\
\hline$<35$ years & $207(62.3)$ & $125(37.7)$ & \multirow{2}{*}{1.11} & \multirow{2}{*}{0.29} \\
\hline$\geq 35$ years & $47(69.1)$ & $21(30.9)$ & & \\
\hline No formal education & $2(50.0)$ & $2(50.0)$ & \multirow{5}{*}{5.52} & \multirow{4}{*}{0.14} \\
\hline Primary & $14(45.2)$ & $17(54.8)$ & & \\
\hline Secondary & $153(64.3)$ & $85(35.7)$ & & \\
\hline Tertiary & $85(66.90)$ & $42(33.1)$ & & \\
\hline \multicolumn{4}{|l|}{ Employment status } & \\
\hline Unemployed & $113(74.8)$ & $38(25.2)$ & \multirow{2}{*}{13.4} & \multirow{2}{*}{0.00} \\
\hline $\begin{array}{l}\text { Employed } \\
\text { Income }\end{array}$ & $141(56.6)$ & $108(43.4)$ & & \\
\hline
\end{tabular}




\begin{tabular}{|c|c|c|c|c|}
\hline Variable & Non-adherent (score 0-5) n (\%) & Adherent (score 6-8) n (\%) & $\overline{X^{2}}$ & Pvalue \\
\hline$<\# 18,000$ & $152(69.1)$ & $68(30.9)$ & \multirow{3}{*}{6.59} & \multirow{3}{*}{0.01} \\
\hline 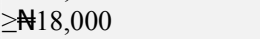 & $102(56.7)$ & 78 (43.3) & & \\
\hline Husband's occupation & & & & \\
\hline Unemployed & $240(99.6)$ & $1(0.4)$ & \multirow{2}{*}{0.14} & \multirow{2}{*}{$1.00^{*}$} \\
\hline Employed & $141(99.3)$ & $1(0.7)$ & & \\
\hline
\end{tabular}

$*=$ fisher's exact test.

Table 3. Reason for non-adherence to iron and folate supplements.

\begin{tabular}{lll}
\hline Reason & Frequency $(\mathbf{n}=\mathbf{4 0 0})$ & Percentage \\
\hline Forgetfulness & 250 & 62.5 \\
Inconvenience of taking supplements outside home & 83 & 20.8 \\
Pill burden & 48 & 12.0 \\
Cost of medicine & 41 & 10.3 \\
Side effects of taking supplements & 46 & 11.5 \\
Feeling it is not important take supplements & 109 & 27.3 \\
Too bored to take supplements everyday & 177 & 44.3 \\
Unavailability of supplements & 152 & 38.0 \\
\hline
\end{tabular}

Table 4. Association between some obstetric parameters, level of adherence and occurrence of anaemia.

\begin{tabular}{|c|c|c|c|c|}
\hline Variable & Anaemic, n (\%) & Non-anaemic, n (\%) & $X^{2}$ & P value \\
\hline \multicolumn{5}{|l|}{ Age } \\
\hline$<35$ years & $157(47.3)$ & $175(52.7)$ & \multirow{3}{*}{0.23} & \multirow{3}{*}{0.63} \\
\hline$\geq 35$ years & $30(44.1)$ & $38(55.9)$ & & \\
\hline \multicolumn{3}{|l|}{ Type of gestation* } & & \\
\hline Singleton & $176(45.6)$ & $9(81.8)$ & \multirow{3}{*}{6.11} & \multirow{3}{*}{0.04} \\
\hline Multiple & $210(54.4)$ & $2(18.2)$ & & \\
\hline \multicolumn{3}{|l|}{ Gestational age } & & \\
\hline First trimester & $2(100.0)$ & $0(0.0)$ & \multirow{4}{*}{6.41} & \multirow{4}{*}{0.04} \\
\hline Second trimester & $25(35.7)$ & $45(64.3)$ & & \\
\hline Third trimester & $161(49.1)$ & $167(50.9)$ & & \\
\hline \multicolumn{3}{|l|}{ Adherence group } & & \\
\hline Non-adherent & $131(69.7)$ & $57(30.3)$ & \multirow{2}{*}{5.85} & \multirow{2}{*}{0.02} \\
\hline Adherent & $123(58.0)$ & $89(42.0)$ & & \\
\hline
\end{tabular}

$*=\mathrm{n}=388$.

\section{Discussion}

The physiologic demands of pregnancy are diverse with an increase in the recommended dietary allowance for iron and folate being inclusive. [12] This forms the basis for WHO recommendation to give supplemental iron and folate to pregnant women in order to forestall the occurrence of anaemia in them. Despite such recommendation, the prevalence of anaemia, especially in low socio-economic climes like ours, is still high. [13] We set out to determine if our study participants were adherent to taking iron and folate supplements, and related this to the occurrence of anaemia within set adherence groups.

A high level of non-adherence (63.5\%) was found among the studied pregnant women. The findings of Ibrahim et al was similar to ours though they used self-report and pill count to assess adherence. [14] Higher and lower values than we observed have however been reported across Africa. [15-17] Gainfully employed women and those who earned above the Nigerian minimum wage were more adherent to taking supplements $(\mathrm{p}=0.00$ and 0.01 , respectively). An inference that a person's financial status contributes to his level of adherence can then be drawn from this statistically significant finding of ours. A higher income and being employed have been associated with adherence to medication use in patients with chronic medical conditions. $[18,19]$ Ibrahim et al and $\mathrm{Ba}$ et al equally reported income as a significant independent positive predictor of adherence in the pregnant women they studied. $[14,20]$ The institution of a national health insurance scheme and other collaborative health programs to reduce the financial burden of healthcare on Nigerians can help to improve adherence to medications. [21] This improves availability and affordability of medications to all, as the rich help to pay for the poor through pooled contributions into the scheme. Our study failed to prove that higher level of education is associated with better compliance to supplements, though most of the study population comprised women with post-primary level of education. Most authors have established from their works that formal education improves adherence. It is believed that more educated women can read and are therefore more enlightened on the importance of taking iron and folate as well as the consequences otherwise. [22-24]

The main reason given for non-adherence in our study was forgetfulness (62.5\%). Most authors have reported this as one of the first three reasons for non-adherence in their study, with even higher values than we report. $[14,20,25]$ Measures to assist women to remember taking these pills 
need to be reinforced. These include health talks at antenatal visits and on social media platforms, family support/reminders, directly observed therapy, pill diary, joining pregnancy clubs, amongst others. [14, 26] The women we studied also found it a burden to take supplements daily (44\%), had no pills available to use $(38 \%)$ or did not know the importance of taking the prescribed supplements $(27 \%)$. The need for continuous education on the benefits of taking these pills regularly and making them available in government health facilities, which most of our population use, cannot be overemphasized. Studies have shown that compliance is better when these supplements are given freely to women at antenatal visits than in places where clients have to source them on their own. $[9,27]$

The prevalence of anaemia we found $(46.8 \%)$ was higher than earlier reports by Ikeanyi and Ibrahim $(37.6 \%)$ in Benin as well as Omote et al $(32.2 \%)$ in Warri. [28, 29] Though Ikeanyi and Ibrahim had a larger sample size than ours, theirs was a retrospective study. Omote et al had studied fewer and more elderly women than in this study. Closer reports to ours were however found in Gombe (northern Nigeria), Nepal and Tanzania with prevalence of anaemia being $51.8 \%, 42.6 \%$ and $47.4 \%$ respectively. [30-32] We observed that most participants had a mild anaemia, with fewer cases of moderate anaemia but none with severe anaemia. This was in agreement with most authors' reports within Nigeria and some other low socio-economic climes, though some cases of severe anaemia were equally found among the pregnant women they studied. [28, 29, 33]

Pregnant women with multiple gestation had a higher prevalence of anaemia than those with singleton gestation $(p=0.04)$. This is as expected since more foetal mass means more iron and folate demand in pregnancy. [34] We also found that occurrence of anaemia reduced as the gestational age increased $(\mathrm{p}=0.04)$, with a slight difference in second trimester, perhaps due to difference in the cut off $\mathrm{Hb}$ $(10.5 \mathrm{~g} / \mathrm{dl})$ for anaemia at this stage of pregnancy. [34] The requirement for iron increases as pregnancy advances due to changes in red cell mass. This iron demand is more apparent in the second trimester and may account for lower $\mathrm{Hb}$ at this stage, hence a lower cut off recommended for anaemia diagnosis. [4, 34] Our finding was however skewed as we had just two women in their first trimester, attributed to the fact that most women book late for antenatal care in our society.

The occurrence of anaemia was more with women nonadherent to taking their supplements $(p=0.0)$, a similar finding to that of Ibrahim et al, though not statistically significant $(p=0.12)$. [14] Other studies have also shown that lack of iron supplementation increases the risk of maternal anaemia as well as its foetal consequences. [35, 36] This finding is as expected since most women in our environment require these supplements to boost their dietary supply of iron and folate due to already established increased demand (in pregnancy) as well as poor supply from the inadequate diet we take in this environment. [34, 37]

We considered the following as limitations of this study: the use of a self-report tool, which may over-estimate the level of adherence reported. This was however chosen for ease and the fact that participants had to source their own supplements independently. Secondly, the study population comprised of more women in late gestation because most women book late for antenatal care. This may give rise to a skewed data and inference drawn from the study.

\section{Conclusion}

In conclusion, there remains a high level of non-adherence to the use of iron and folate supplements in pregnancy. This is because pregnant women usually forget to take these pills. A higher financial status is associated with improved pill adherence, therefore gainful employment of women is solicited. The prevalence of anaemia in pregnancy is still high and is influenced by non-adherence to iron and folate use. Measures to improve adherence should be reinforced at antenatal visits.

\section{Conflict of Interest}

All authors do not have any possible conflict of interest.

\section{Acknowledgements}

We are grateful to all the women who participated in the study as well as the ad-hoc staff who assisted with logistics for the study.

\section{References}

[1] World Health Organization. Adherence to long-term therapies: evidence for action. Geneva, Switzerland, 2003.

[2] DiMatteo M. R. (2004). Variations in patients' adherence to medical recommendations: a quantitative review of 50 years of research. Medical Care, 42: 200-209.

[3] WHO guidelines. Daily iron and folate acid supplementation in pregnant women. World Health Organization. Geneva, 2012.

[4] de Benoist B., McLean E., Egli I. and Cogswell M. (2008). Worldwide Prevalence of Anaemia 1993-2005: Who Global Database on Anaemia. WHO, Geneva, Switzerland.

[5] Kumar P., Pore P. and Patil U. (2012). Maternal anemia and its impact on perinatal outcome in a tertiary care hospital of Pune, in Maharashtra. Indian Journal of Basic and Applied Medical Research, 1: 111-119.

[6] World Health Organization. Standards for Maternal and Neonatal Care: Iron and Folate Supplementation: World Health Organization, 2006.

[7] Mengist, H. M., Zewdie, O., and Belew A. (2017). Intestinal helminthic infection and anaemia among pregnant women attending ante-natal care (ANC) in East Wollega, Oromia, Ethiopia. BMC Research Notes, 10: 440. https://doi.org/10.1186/s13104- 017-2770-y. 
[8] B. Taye, G. Abeje, and A. Mekonen, (2015). "Factors associated with compliance of prenatal iron folate supplementation among women in Mecha district, Western Amhara: a cross-sectional study." Pan African Medical Journal, 20: 43.

[9] Ugwu E. O., Olibe A. O., Obi S. N. and Ugwu A. O., (2014). "Determinants of compliance to iron supplementation among pregnant women in Enugu, Southeastern Nigeria," Nigerian Journal of Clinical Practice, 17: 608-612.

[10] Morisky, D., Green, L., and Levine, D. (1986). Morisky Medication Adherence Scales: MMAS-4 and MMAS-8 MMAS-8 1), $8 . \quad$ Retrieved from https://www.thenationalcouncil.org/wpcontent/uploads/2017/0 3/5_Morisky_Medication_Adherence-Scale.pdf.

[11] Nigerian National Minimum wage amended Act (2011). Available at www.ilo.org $>$ docs.

[12] Kominiarek M. A., and Rajan P. (2016) Nutrition Recommendations in Pregnancy and Lactation. Medical Clinics of North America, 100: 1199-1215.

[13] Idowu O. A., Mafiana C. F., and Dapo S. (2005). Anaemia in pregnancy: A survey of pregnant women in Abeokuta, Nigeria. African Health Scencesi, 5: 295-299.

[14] Ibrahim Z. K., Abd El-Hamid S., Mikhail H., and Khattab M. S. (2011). Assessment of Adherence to Iron and Folic Acid Supplementation and Prevalence of Anaemia in Pregnant Women. Medical Journal of Cairo University, 79: 115-121.

[15] Seck B. C., and Jackson R. T. (2008). Determinants of compliance with iron supplementation among pregnant women in Senegal. Public Health Nutrition, 11: 596-605.

[16] Kiwanuka T. S., Ononge S., Kiondo P., and Namusoke F. (2017). Adherence to iron supplements among women receiving antenatal care at Mulago National Referral Hospital, Uganda-cross-sectional study. BMC Research Notes, 10: 510.

[17] Sawicki E., Stewart K., Wong S., Leung L., Paul E., and George J. (2011). Medication use for chronic health conditions by pregnant women attending an Australian maternity hospital. Australian and New Zealand Journal of Obstetrics and Gynaecology, 51: 333-338.

[18] Osborn C. Y., Kripalani S., Goggins K. M., and Wallston K. A. (2017). Financial Strain is Associated with Medication Nonadherence and Worse Self-rated Health among Cardiovascular Patients. Journal of Health Care for the Poor and Underserved, 28: 499-513.

[19] Fernandez-Lazaro C. I., Adams D. P., Fernandez-Lazaro D, Garcia-González J. M., Caballero-Garcia A., and MironCanelo J. A. (2018). Medication adherence and barriers among low-income, uninsured patients with multiple chronic conditions. Research in Social and Administrative Pharmacy, https://doi.org/10.1016/j.sapharm.2018.09.006.

[20] Ba D. M., Ssentongo P., Kjerulff K. H., Na M., Liu G., Gao X., and Du P. (2019). Adherence to Iron Supplementation in 22 Sub-Saharan African Countries and Associated Factors among Pregnant Women: A Large Population-Based Study. Current Developments in Nutrition, 3: 120.

[21] Ministry of Health, Federal Republic of Nigeria. National Health Insurance Scheme 2006.

[22] Titilayo A., Palamuleni M. E., and Omisakin O. (2016).
Sociodemographic factors influencing adherence to antenatal iron supplementation recommendations among pregnant women in Malawi: analysis of data from the 2010 Malawi Demographic and Health Survey. Malawi Medical Journal, 28: $1-5$.

[23] Agegnehu G., Atenafu A., Dagne H., and Dagnew B. (2019). Adherence to iron and folic acid supplement and its associated factors among antenatal care attendant mothers in Lay Armachiho health centers, Northwest, Ethiopia. International Journal of Reproductive Medicine, 2019: 5863737.

[24] Nisar Y. B., Dibley M. J., and Mir A. M. (2014). Factors associated with non-use of antenatal iron and folic acid supplements among Pakistani women: a cross sectional household survey. BMC Pregnancy and Childbirth, 14: 305.

[25] Fouelifack F. Y., Sama J. D., and Sone C. E. (2019). Assessment of adherence to iron supplementation among pregnant women in the Yaounde gynaeco-obstetric and paediatric hospital. Pan African Medical Journal; 34: 211. doi: 10.11604/pamj.2019.34.211.16446.

[26] Matsui D. (2012). Adherence with drug therapying Pregnancy. Hindawi Obstetrics and Gynaecology International. Article ID 796590; 1-5. Doi: 10.1155/2012/796590.

[27] Binetou C. S., and Robert T. J. (2008). Determinants of compliance with iron supplementation among pregnant women in Senegal. Public Health Nutrition, 11: 596-605.

[28] Ikeanyi E. M., Ibrahim A. I. (2015). Does antenatal care attendance prevent anemia in pregnancy at term? Nigerian Journal of Clinical Practice, 18: 323-327.

[29] Omote V., Ukwamedua H. A., Bini N., Kashibu E., Ubandoma J. R., and Ranyang A. (2020). Prevalence, Severity, and Correlates of Anaemia in Pregnancy among Antenatal Attendees in Warri, South-Southern Nigeria: A CrossSectional and Hospital-Based Study. Hindawi Anaemia. Article ID 1915231, $1-7$. https://doi.org/10.1155/2020/1915231.

[30] Bukar M., Audu B. M., Yahaya U. R., and Melah G. S. (2008) Anaemia in pregnancy at booking in Gombe, North-Eastern Nigeria. Journal of Obstetrics and Gynaecology, 28: 775-778.

[31] Marahatta R. (2007). Study of anaemia in pregnancy and its outcome in Nepal Medical College Teaching Hospital, Kathmandu, Nepal Nepal Medical College Journal, 9: 270274.

[32] Msuya S. E., Hussein T. H., Uriyo J., Sam N. E., and StrayPedersen B. (2011). Anaemia among pregnant women in Northern Tanzania: Prevalence, risk factors and effect on perinatal outcomes. Tanzanian Journal of Health Research, 13: 33-39.

[33] Sholeye O. J., Animashaun V. J., and Shorunmu T. O. (2017). Anaemia in pregnancy and its associated factors among primary care clients in Sagamu, Southwest, Nigeria: A facility-based study. Journal of Family Medicine and Primary Care, 6: 323-329.

[34] Bothwell T. H. (2000). Iron requirements in pregnancy and strategies to meet them. American Journal of Clinical Nutrition, 72: 257S-264S.

[35] Pena-Rosas J. P., De-Regil L. M., Dowswell T., and Viteri F. E. Daily oral iron supplementation during pregnancy. The Cochrane Database Systematic Review. 2012; 12: Cd004736. 
[36] Habib F., Alabdin E. H., Alenazy M., Nooh R. (2009). Compliance to iron supplementation during pregnancy. Journal of Obstetrics and Gynaecology, 29: 487-492.

[37] Lindsay K. L., Gibney E. R., and McAuliffe F. M. (2012).
Maternal nutrition among women from Sub-Saharan Africa, with a focus on Nigeria, and potential implications for pregnancy outcomes among immigrant populations in developed countries. Journal of Human Nutrition and Diet, 25: 534-546. 